\title{
Practice and Research on the Teaching of Organic Chemis- try in Colleges and Universities
}

\section{Jing Sun}

School of Chemistry \& Chemical Engineering, Yangzhou University, Yangzhou, Jiangsu, 225002, China

\begin{abstract}
Organic chemistry is a basic course of chemistry and chemical engineering in colleges and universities. It has the characteristics of great difficulty, many knowledge points, rapid development and so on. In the classroom teaching of organic chemistry, the education of viewpoint, attitude and scientific spirit must be run through to promote students interest and enthusiasm in learning.
\end{abstract}

\section{Keywords}

quality education; organic chemistry; classroom teaching

\section{Fund Project}

"Brand Professional Construction Project Funding Project of Universities and Colleges in Jiangsu Province" (Project No.: PPZY2015B112)

\section{普通高校有机化学课堂教学中的实践与研究}

孙晶

扬州大学化学化工学院，中国・江苏扬州 225002

\section{摘 要}

有机化学是高等学校化学、化工等专业的一门专业基础棵, 具有难度大、知识点多、发展快等特点。在有机化学课堂教学中, 观点、态度和科学精神的教育必须贯穿其中, 从而提升学生的学习兴趣和热情。

关键词

素质教育; 有机化学; 课堂教学

基金项目

“江苏高校品牌专业建设工程资助项目”（项目编号：PPZY2015B112）

1 引言

高等教育是培养高等专业人才的主要基地，相对基础教 育和成人教育，有着独特的优势：充足的富有创造力和想象 力的研究思想 (广大大学教师所具备)、丰富的教学资源（图 书馆、网络、现代教学设备等）、具有巨大发展潜力的教育 对象和学习主体 (青年大学生)。高等教育更能发挥知识传播、 应用及创新功能，更能很好的实施素质教育 ${ }^{[1-2]}$ 。

大学生处于青年时期，思维方式初步形成，人生观、世 界观已具维形, 他们有着强烈的发展、学习的渴望。他们不 需要空洞的说教，渴望的是一种潜移默化的影响。老师在教 学过程中如把教学过程和育人过程融为一体, 以一定素材为
载体对大学生进行素质教育会更为有效。

有机化学是高等学校化学、化工等专业的一门重要的专 业基础课。该课程的内容多、范围广、发展快, 教师难教, 学生难学 ${ }^{[3]}$ 。在课堂教学中, 如能够将知识讲活, 使学生易学、 易懂, 并在教学过程中对学生进行其它素质的培养与引导, 对有机化学的教与学是至关重要的。

\section{2 在有机化学课堂教学中渗透世界观的教育}

有机化学是一门理论性和实践性较强的基础学科, 有机 化学的教学目的是使学生系统地了解和掌握有机化合物的组 成、结构、性质、合成以及相关理论; 培养学生的良好的思 维方式。有机化学理论抽象、知识繁杂、机理深奥、前沿研 
究发展迅猛, 使这门课程在教师授课和学生学习中遇到了较 大挑战 ${ }^{[4-7]}$ 。学习研究和分析这些众多的纷繁复杂的有机物, 会帮助学生客观地认识世界, 在有机化学教学过程中, 教师 要注意引导和影响学生正确的世界观形成。世界是物质的, 物质是有规律的, 它们之间是可以相互转化的, 不同的物质 具有不同的结构和功能……这些都不是教条, 它们是客观的、 实实在在的存在，是自然界的客观规律。教学过程中无需过 多的语言去阐述，要引导学生自己去体会、去思考，从而形 成正确的方法学和世界观。

在讲授 “同系列” 概念时, 阐述它是有机化学中的一个 重要基本概念, 同系列中化合物的结构相似, 从而具有相似 的化学性质, 只要研究同系列中的一、二个典型的化合物的 结构与性质, 就能初步推知其它化合物的结构与性质; 反之, 只要知道化合物属于哪个系列, 就能推测它大致有些什么性 质。同时，告诉学生必须辨证地看待此概念，必须注意同系 列中的个性和共性，正确理解两者的关系。

\section{3 充分利用化学史对学生进行科学精神教育}

科学史实, 特别是科学家的成长是最具教育价值的教学 资源之一。在有机化学课堂教学中, 可以通过化学家的研究 历程的介绍, 让学生从中汲取营养, 养成自信和科学的精神 ${ }^{[8]}$ 。 在讲授醛、酮化学性质时, 把人名反应 “沃尔夫 - 凯惜纳 黄鸣龙反应” 中黄鸣龙教授如何不畏科学权威、改进此反应 的经过介绍给学生, 使学生从黄鸣龙教授身上学习到追求真 理、崇尚真理的科学精神。同时又告诉学生, 在所有的有机 化学人名反应中, 出现中国人的名字仅此一例, 而且, 在国 际上的一些教学参考书上, “黄鸣龙” 这三个字有时还不会 出现, 由此来教育和培养学生的爱国敬业的品德。

在讲授有机波谱分析法这一章时，在比对有机波谱分析 法与经典的化学分析法在结构分析方面的优势时, 举例说明 吗啡从鸦片中提取出来到最后确定结构大约经历了 150 年, 若采用现在所学的波谱分析法数分钟结构即可确定，从而激 发学生学习本章的兴趣。

创新精神是最重要的科学精神之一, 培养学生的创新精 神不是一朝一夕的事, 需要足够的知识咜备和敢于突破陈规 的内在品格。在有机化学教学中, 可以通过追踪科学家的研 究足迹, 探索科学家的创造过程, 学习科学家的创新精神,
激发学生的学习兴趣和创新欲望。

\section{4 以问题激发学生学习、思考和研究}

大学生具有较好的思维能力, 较强的自我学习能力。在 课堂教学中, 教师是主导者, 学生是学习主体。在教学中教 师要注意调动学生学习的积极性, 充分发挥学生的学习主体 性, 激发学生的学习能力。通过创设问题情景, 激发学生思维; 以问题为先导，充分开发学习潜能。

有机化学教学内容多, 教师不可能在有限的课堂教学时 间内, 把所有的知识点都讲到。教与学是双面的, 需要把有 机化学的学习延伸到课堂之外。在有机化学教学中, 经常把 问题抛给学生, 让其课后查阅资料、讨论、研究, 使学生养 成自我学习的习惯, 并在后续的课堂教学中加以归纳和总结。 在讲授化合物的变旋光的概念时, 让学生查资料列举具有变 旋光的化合物，并从结构理论上加以解释。

有机酸是烃类分子中的氢原子被羧基取代的衍生物，那 么酸的化学性质可以通过对酸的结构分析来推测。酸的结构 式（见图 1 ），通过结构延伸到其化学性质：酸性、取代反应、 脱羒反应、 $\alpha-\mathrm{H}$ 取代反应，最后，具体讲解酸的化学性质。

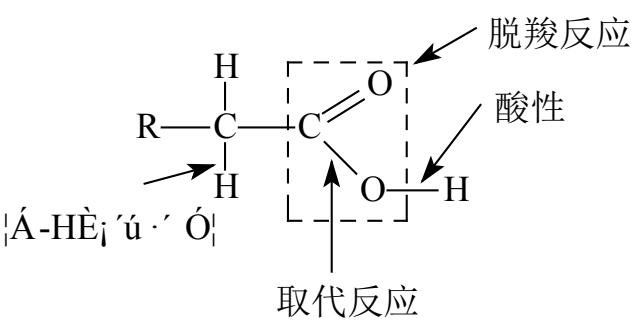

图 1 酸的化学性质

\section{5 提高学生的课堂参与度}

参与式教学是一种以学生为中心, 教师运用不同的教学 手段和灵活多样直观形象的教学方法, 激励学生的学习热情, 充分调动学生的学习积极性与主动性, 使之成为学习的积极 参与者实践者的教学方法。与传统讲授式教学相比, 参与式 教学对教师提出了更高的要求。

有机化合物结构复杂、种类繁多，同分异构体现象普遍 存在, 需要给每种化合物一个准确且简便的反映出其组成和 结构的名称, 对有机化合物的命名是学习有机化学的基础和 前提。在学习有机化合物命名时, 要遵循相应的规则, 以保 证命名的规范与正确。在教学过程中, 发现学生的化合物的 
命名的正确率不超过 $60 \%$, 不是丢三落四, 就是画蛇添足, 导致命名错误。针对学生的这些情况，在讲授醋酮化合物的 命名后，笔者做了一个教案，让学生 8 人一个小组，自行制 作讲义和课件说明命名化合物时需注意的事项和规则, 在课 堂上随机抽取学生进行讲解, 由此锻炼了学生, 并对有机化 合物的命名有了更深的理解和掌握。

化学是一门与人类生活密切相关的学科, 在有机化合物 各类别讲解时, 将其在生活生产上的应用介绍给学生, 让学生 感受到有机化学的知识就在我们的日常生活中。在讲授醇的氧 化性质时，通过对交通违章处理中是否是酒后驾驶最简单可行 的方法是现场检测驾驶人员呼气中的酒精含量, 要测量酒精含 量就要用到酒精检测仪。酒精检测仪的原理就是六价铬在强酸 性条件下能将乙醇氧化, 自身被还原为三价铬, 溶液变为绿色, 方法简便而科学，实用性强，提高了学生的学习兴趣。

\section{6 结语}

高等教育要顺应时代、跟上改革的发展步伐, 要求我们 必须在教育的每一个环节进行改革和探索，使我们的高等教 育真正实现培养人、教育人、发展人的目标，为科学的发展 和国家的富强打好基础。因为 “办好高等教育, 事关国家发展、
事关民族未来。”（摘自习近平祝贺清华大学建校 105 周年 的贺信）。

\section{参考文献}

[1] 于姗姗. 大学有机化学基础课程的教学反思. 高校讲坛 2014 (3): $100-101$.

[2] 陈艳雪, 杨晋辉. 浅谈如何激发学生学习有机化学的兴趣浅. 科技 教育创新, 2012(22):226。

[3] 拱树文, 潘兆岭, 史阳等. 提高有机化学课堂教学质量的几点实践. 广州化工 ,2018,46(7):153-155.

[4] 曾敬, 康懈红, 田鹏, 苏桂田. 以培养学生自主学习能力为目 标的有机化学教学模式探索. 沈阳师范大学学报 (自然科学 版 ),2017,35(4):504-507.

[5] 孙婷, 赵光, 张启俭. 浅析对高校有机化学教学改革的几点思考. 中 国校外教育, 2014(12):45-46.

[6] 刘文锋, 黎奸文, 李永莲. 有机化学教学方法改革的探索与实践. 山 东化工 ,2018,47(06): 143- 144.

[7] 张静, 赵宇. 有机化学课堂中激发学生学习兴趣的教学探索与实 践. 山东化工, 2017,46(23):123-124.

[8] 包永胜. 浅谈有机化学教学中如何提高学生创新意识. 内蒙古石 油化工 ,2018(1):67-68 